\title{
UM OLHAR SOBRE A TRAJETÓRIA DO MUSEU DE CIÊNCIA RICARDO FERREIRA
}

\section{Carlos Wagner Costa AraúJo}

Universidade Federal do Rio Grande do Sul

E-mail: wagneraraunivasf@gmail.com

\section{MARcos ANTONIO PINTO RIBEIRO}

Escola de Referência em Ensino Médio Maria Wilza Barros de Miranda

E-mail: marcosapribeiro@gmail.com

\section{LINDSAI SANTOS AMARAL BATISTA}

Secretaria Estadual de Educação da Bahia

E-mail: amaral.lindsai@gmail.com

\section{YURI RAFAEL ALVES SOBRAL}

Universidade Federal Rural de Pernambuco

E-mail: yurisobral9@gmail.com

\section{RESUMO}

Neste estudo, que tem característica da pesquisa qualitativa, discutimos os caminhos teóricos, metodológicos e trajetória do Museu de Ciência Ricardo Ferreira - MCRF, a partir de discussões realizadas no Mestrado em Educação em Ciências: Químicas da Vida e Saúde da Universidade Federal do Rio Grande do Sul - UFRGS. O Museu fica localizado na Escola de Referência Estadual Otacílio Nunes de Souza (EREMONS), Petrolina, sertão de Pernambuco. Um dos objetivos é tentar responder o seguinte problema: como as atividades de educação científica e popularização da ciência, pautadas em preceitos freireanos, podem contribuir para a cultura científica e o ensino de ciências de jovens estudantes e professores da comunidade escolar, em questão? O MCRF, foi fundado no ano de 2012, em 2015, começou a fazer parte do Projeto Político Pedagógico da escola, que é de educação em tempo integral. O texto está organizado em discussões teóricas, ações, análises do percurso e trajetória do MCRF, numa discussão sobre a perspectiva de um espaço não formal dentro de uma escola de ensino médio da educação básica. A construção de um espaço não formal, com a pedagogia da pergunta, temas geradores e dialogicidade em Freire, vem proporcionando a aprendizagem dos jovens estudantes, através de argumentos, assim como conflitos e a construção de conceitos científicos, antes considerados trágicos.

\section{PALAVRAS-CHAVE:}

Educação Científica; Divulgação Científica; Educação Não Formal. 
ABSTRACT

In this study, which is characteristic of qualitative research, we discuss the theoretical, methodological and trajectory of the Ricardo Ferreira Science Museum - MCRF, based on discussions held in the Master in Science Education: Chemistry of Life and Health at the Federal University of Rio Grande of the South - UFRGS. The Museum is located at the State Reference School Otacilio Nunes de Souza (EREMONS), Petrolina, in the hinterland of Pernambuco. One of the objectives is to try to answer the following problem: how can scientific education and science popularization activities, based on Freirean precepts, contribute to the scientific culture and science teaching of young students and teachers from the school community in question? MCRF was founded in 2012, in 2015, it became part of the school's Political Pedagogical Project, which is full-time education. The text is organized in theoretical discussions, actions, analysis of the path and trajectory of the MCRF, in a discussion about the perspective of a non-formal space within a high school of basic education. The construction of a non-formal space, with the pedagogy of the question, generative themes and dialogicity in Freire, has provided the learning of young students, through arguments, as well as conflicts and the construction of scientific concepts, previously considered tragic.

\section{KEYWORDS:}

Scientific Education; Scientific Dissemination; Non Formal Education.

\section{INTRODUÇÃO}

A formação de uma cultura científica dos jovens é um desafio que perpassa pela escola e pela vida. A educação integral vai além da escola e pode ocorrer em museus, zoológicos, praças, planetários, observatórios e na rua. Mas como organizar um centro ou museu de ciência? No Brasil, são conceitos em discussão, há algumas décadas, onde os museus de ciência estão associados ao colecionismo e os centros de ciência, à formação e à interação. No entanto, museu ou centro de ciência são espaços lúdicos, dinâmicos e interativos, sendo que o museu, ao se referir ao contexto da ciência, não é mais lugar de coisas antigas e históricas (JACOBUCCI, 2006; VALENTE, CAZELLI e ALVES, 2005; PAVÃO, 2008).

A partir da Segunda Guerra Mundial e do lançamento do satélite artificial Sputnik, os objetos históricos vão ficando em segundo plano (GASPAR, 2002). Ao invés de focar no passado, a maioria dos novos museus e centros de ciência passou a se preocupar com o presente e o futuro. Muitos deles não têm qualquer acervo histórico: as coleções de objetos antigos foram substituídas por experimentos destinados a mais envolvimento do visitante, bem como fornecer informações, possibilitar a 
aprendizagem e trazer mais perguntas, do que respostas, além da ênfase no desenvolvimento científico e tecnológico.

A história dos museus de ciência no Brasil é repleta de contradições. Em alguns momentos incentivados pelos governos, em outros períodos, o abandono, precarização dos espaços, gerando riscos de acidentes e perda do acervo. Consideramos a década de 60, um período de intensa movimentação para a criação dos centros de ciências. No entanto, nesse período, o enfoque foi a formação de professores, tendo como referencial o acordo firmado entre o Ministério da Educação e a Agência Internacional dos Estados Unidos para o Desenvolvimento, chamado como Acordo MEC-USAID, que objetivava introduzir uma formação técnica e profissionalizante, tendo o modelo educacional americano como ideal para o Brasil. Esse acordo gerou muitas controvérsias. Durante este período, seis centros de ciências foram implantados nos estados brasileiros, no Nordeste destacamos 02 dois: o Centro de Ensino de Ciências da Bahia - CECIBA - Salvador/BA; e Centro de Ensino de Ciências do Nordeste - CECINE - Recife/PE (VALENTE; CAZELLI; ALVES, 2005).

Ainda no Nordeste, especificamente no ano de 1979, foi instalado em Salvador, o Museu de Ciência e Tecnologia da Bahia - MCT/BA que, de fato, foi o primeiro do Brasil e da América Latina. O espaço interativo nasceu antenado com a proposta museológica que valorizava a interatividade direta, caracterizada com hands on, do Exploratorium de São Francisco (FERREIRA, 2014). O pioneirismo e ousadia dos baianos ainda são ratificados através do envio de profissionais para a Europa e Estados Unidos, com a finalidade de conhecer as experiências educacionais dos principais espaços.

O espaço baiano ainda serviu de modelo para instituições semelhantes em São Paulo e Rio Grande do Sul. O MCT/BA contou com o apoio do Conselho Britânico, instituição do Reino Unido de fomento a países em desenvolvimento. Ainda durante a 
década de 70, um dos diretores do museu de ciência inglês, veio ao Brasil para discutir a concepção, a implantação do modelo e formato pedagógico (LIBÓRIO, 2014).

No estado de Pernambuco, em 1994, foi inaugurado o Espaço Ciência como um programa da Secretaria de Ciência e Tecnologia do governo do estado de Pernambuco. A criação foi fomentada por um edital da Capes, o Subprograma de Educação e Ciência - SPEC da Capes, que propunha a montagem de museus de ciência no Brasil.

Nesse contexto, com a instalação da Universidade Federal do Vale do São Francisco - UNIVASF, na região, em 2004, se iniciou um movimento de criação de espaços da educação não formal. A implantação do Espaço Ciência e Cultura (ECC) fez parte da política pública indutora da UNIVASF, para a popularização da ciência, que provocou, de forma singular e peculiar, o fazer divulgação científica no Vale do São Francisco, com atividades de arte e ciência. Neste espaço foram realizadas atividades para milhares de pessoas, com ações anuais, a exemplo da Semana Nacional de Ciência e Tecnologia, Mostra Científica do Semiárido, Exposições de Ciência e Tecnologia, além do Teatro Científico.

O ECC foi polo do programa nacional "ABC na Educação Científica: Mão na Massa", que foi uma rede composta por 12 instituições nacionais, apoiada através da Academia Brasileira de Ciências - ABC, com foco na formação continuada para professores da educação infantil e de ciências, da educação básica. Todo esse movimento provocou um investimento de mais 5 milhões de reais, na construção de um prédio para a instalação do ECC, à margem do Velho Chico, na cidade de PetrolinaPE. O prédio foi objeto de muita discussão no meio acadêmico. O primeiro desafio foi superado: a construção do espaço, portanto a manutenção sempre foi um desafio dos museus de ciência no Brasil. A cidade, ainda contou com o Núcleo Municipal de Ensino de Ciências - NUMEC, vinculado à Secretaria de Educação de Petrolina. 
Essas duas primeiras décadas do século XXI são marcadas pelo crescimento dos espaços culturais e científicos. Para Massarani (2015, p. 06),

Desde a segunda edição do Guia de Centros e Museus de Ciência do Brasil, em 2009, houve um aumento de $41 \%$ do número de instituições, passando de 190 para 268. Desse total, 155 estão no Sudeste; 44, no Sul; 43, no Nordeste; 15, no Centro-Oeste; e 11, no Norte. Como se pode ver, a distribuição regional permanece desigual, mas nota-se crescimento em algumas regiões antes mais desfavorecidas. Embora o crescimento seja expressivo, a concentração na região Sudeste persiste.

Diante dessa contextualização, esse artigo pretende responder à seguinte questão: Como os projetos de educação científica e popularização da ciência do Museu de Ciência Ricardo Ferreira - MCRF/PE, pautados em preceitos freireanos como a Pedagogia da Pergunta e os Temas Geradores e Dialógicos, relacionam-se com a comunidade e com a escola onde o museu foi instalado?

O artigo foi desenvolvido a partir da experiência do MCRF/PE, levando em consideração o movimento recente de criação de um museu de ciência e de divulgação científica na Escola. O espaço, em 2012, foi homenageado com o nome do professor da UFPE, o pernambucano Ricardo de Carvalho Ferreira, um grande químico, divulgador e incentivador da ciência na região nordeste. No espaço não se perde a forma de divulgar ciência para todos os públicos, preceito seguido por Ricardo Ferreira. Além de provocações como: "Pode Malinar", "É para Bulir", "Proibido não Tocar" e "Pode Mexer". Olhar para a trajetória do MCRF é olhar para o encanto dos jovens para a cultura científica, como no poema de Manoel de Barros:

A ciência pode classificar e nomear os órgãos de um sabiá, mas não pode medir seus encantos. A ciência não pode calcular quantos cavalos de força existem nos encantos de um sabiá. Quem acumula muita informação perde o condão de adivinhar: divinare. Os sabiás divinam [...] (BARROS, 1998, p. 18).

A pesquisa analisou o período de 2012 a 2018, o percurso e trajetória dos integrantes. Mas será que esta experiência tem similaridade com o conceito de Clube de Ciências? Podemos antecipadamente responder aqui que a proposta foi além deste modelo, caracterizando como uma forma singular de fazer ciências e divulgação 
científica, onde cultura, arte e ciência foram entrelaçadas e misturadas, com a vida dos estudantes.

De acordo com Antônio Carlos Pavão, que é pesquisador e divulgador de ciência, em Pernambuco, "[...] a melhor forma de ensinar ciências é fazendo ciência" (PAVÃO, 2008, p. 01), o que permite fazer com que os alunos e professores tenham atitudes e se comportem como cientistas. No entanto, estas atitudes devem ser avaliadas de forma processual, onde os alunos necessitam fazer perguntas sobre uma determinada realidade, experimentar situações que sejam livres, abertas, para a investigação e tomadas de decisões. Com este método os jovens têm a possibilidade de desenvolver habilidades científicas, ter conclusões, planejar, desenhar e construir experimentos (PAVÃO, 2008).

Uma outra forma ensinar e aprender ciências é a metodologia denominada Educação Científica Baseada na Investigação - ECBI, que tem sido desenvolvida em diversos países (CHARPAK; LÉNA; QUÉRÉ, 2006; CARVALHO et al, 1998; SCHIEL, 2005). Propostas de ciências, como a do La Main à La Pâte, ABC na Educação Científica: Mão na Massa, Rede Nacional de Educação e Ciência - Novos Talentos incorporam também no seu fazer, a investigação.

Cabe enfatizar, que a educação científica é a pequena parte de um todo, que é fundamental para o exercício democrático na escola básica. A UNESCO (2000) reforça que "igualdade no acesso à ciência não é somente uma exigência social e ética: é uma necessidade para realização plena do potencial intelectual do homem".

Pavão (2008, p. 03) argumenta que a educação científica deve ser pautada "na experimentação e interação." Dessa forma esta discussão do ambiente não formal dentro do formal, pode contribuir com a educação científica na educação básica, sendo a experiência do MCRF uma estratégia para a Educação Integral. De acordo com (CHARPAK; LÉNA; QUÉRÉ, 2006) os processos de investigação, de experimentação e o 
trabalho coletivo na sala de aula são importantes para socialização, colaboração mútua, o compartilhamento das ideias, planos, conclusões e o fortalecimento da própria compreensão do aluno por meio do diálogo com seus pares.

Um dos idealizadores do Espaço Ciência Viva do Rio de Janeiro, o Maurice Bazin ressalta:

As instituições voltadas para divulgação científica devem ser criadas e pensadas para atender à comunidade local e formar educadores do povo brasileiro. Um bom museu ou centro de ciência, é aquele que contagia o público, como acontece no carnaval: você começa a cantar e de repente está sambando. "Gostaria que as pessoas sambassem ciência", dizia. Neste aspecto o museu seria um dos lugares mais democráticos, exatamente por ser um ambiente de troca e de experiência das diferenças. (FURTADO, 2013, p. 13).

O ensino por investigação pode possibilitar aos alunos uma melhor reflexão sobre a natureza o que fortalece e desenvolve uma emancipação do entendimento dos conceitos científicos. A este respeito Freire (2008) evidencia que:

O ensino por investigação constitui uma orientação didática para o planejamento das aprendizagens científicas dos alunos, reflete o modo como os cientistas trabalham e fazem ciência, dá ênfase ao questionamento, à resolução de problemas, à comunicação e usa processos da investigação científica como metodologia de ensino avaliação de explicações alternativas. (Freire, 2008, p. 105)

O uso de atividades de investigação pode ajudar os alunos a aprender ciência, a fazer ciência e sobre ciência. Neste sentido, o ensino por investigação envolve os alunos na escolha de evidências, permitindo-lhes refletir e responder às questões problematizadas pelo professor de forma que suas respostas tenham um embasamento no conhecimento científico (FREIRE, 2008).

\section{METODOLOGIA}

A pesquisa se caracteriza como qualitativa, porém, com aporte na Pesquisa Participante e Tema Gerador, em Freire (1974; 2008). A investigação teve como ponto 
de partida a problematização de temas científicos, a partir de situações concretas que emergiram no diálogo com a comunidade escolar.

A pesquisa foi desenvolvida em três etapas metodológicas: a primeira etapa foi o levantamento bibliográfico e o estado do conhecimento. A segunda etapa foi uma pesquisa documental, com análise de diários de bordo, e a terceira consistiu em uma pesquisa de campo, com os professores e alunos do MCRF.

Sampieri et al. (2006), destaca que o levantamento bibliográfico alicerça o marco teórico e a construção de uma perspectiva sobre o objeto de pesquisa, e enfatiza a importância desta etapa do trabalho científico. Vale destacar que a pesquisa documental foi de caráter qualitativo com coletas de informações sobre as rotinas do MCRF, objeto de análise no processo de construção, nas reuniões, regulamentos, regimentos, vídeos e textos produzidos, considerados fontes primárias (MARCONI; LAKATOS, 2013).

Deste modo, foram realizadas entrevistas semiestruturadas (TRIVIÑOS, 1987), as quais auxiliaram como instrumentos de coleta de dados para conhecer os aspectos, práticas, perspectivas, desafios, dinâmicas e o desenvolvimento do Museu. A pesquisa qualitativa busca entender aspectos da realidade, assim como capturar significados dos fenômenos manifestados de forma multidimensional (ANDRÉ, 1983).

A pesquisa partiu de uma situação problema real, para análise dos projetos desenvolvidos e objetos construídos, conflitados com os modelos de educação. $\mathrm{Na}$ Pesquisa Participante, a interação, a observação direta, seminários, itinerâncias, planejamento e construção dos experimentos contribuíram para a humanização dos atores. Durante a pesquisa, ainda foram analisados os registros no diário de bordo, fotos e filmagens, a fim de observar o envolvimento, percepção, obstáculos, engajamento e desafios dos participantes. Nos encontros e reuniões foram coletados de vários tipos de dados, como conhecimento prévio, os problemas propostos, Tema 
Gerador, concepção, conceitos iniciais e discussões, para a construção do experimento para exibição (FREIRE, 1974).

Para a coleta de dados foi desenvolvido um questionário estruturado e semiestruturado, para verificar se a construção e participação de um Museu de Ciência dentro de uma escola pode modificar a forma de pensar e agir dos estudantes e professores? Segundo Manzini (2004), o modelo estruturado contém perguntas fechadas, que se assemelham a formulários, apresentando-se inflexível, já o semiestruturado possui uma flexibilidade devido a suas questões abertas.

Para Moreira e Caleffe (2006), apesar de existir uma grande quantidade de instrumentos para coleta de dados, o questionário é muito popular e de fácil entendimento. Neste caso, com o questionário o pesquisador pode ganhar tempo, impessoalidade, garantia de uma grande taxa de retorno, além de ter a possibilidade de personalizar as perguntas.

\section{RESULTADOS E DISCUSSÃO}

A ideia de um espaço para divulgação científica, itinerância, envolvimento dos alunos da educação básica numa escola pública, bem como a criação de um museu em um espaço formal, foi uma provocação ao modelo de educação tradicional e bancária, presente em muitas escolas. Em entrevista com um dos professores que coordenava as atividades do MCRF, o mesmo fala sobre a sua trajetória e experiência em construir experimentos de física durante a graduação na Universidade Federal Rural de Pernambuco - UFRPE e enquanto bolsista de Apoio Técnico em Extensão no País - ATP, financiada através do Conselho Nacional de Desenvolvimento Científico e Tecnológico - CNPq, coordenada pelo Espaço Ciência e Cultura/UNIVASF contribuíram para a consolidação da ideia. Para ele a educação científica:

Quadro 1: Resposta de um dos coordenadores com relação à metodologia do MCRF Fonte: Dados da Pesquisa. 
Professor 1: "A ideia não é formar cientistas ou pesquisadores, mas difundir conhecimentos, atitudes e valores associados à postura indagativa e crítica própria das ciências. Nem que o conhecimento científico seja apresentado de forma pronta e acabada aos alunos, mas construído por eles por meio da investigação e da experimentação sem perder o malinar, mexer, bulir, para aceitação entre os estudantes da escola. Os alunos passam a ser protagonistas na construção do conhecimento e deixam de ser tábua rasa."

É perceptível na fala do Professor 1, preceitos em Freire (2008), onde os sujeitos buscam dar significado às coisas, com as quais a transformação é consolidada na práxis social, que vai além do ato de trocar ideias. O verdadeiro diálogo não pode existir se os que dialogam, não se comprometem com o pensamento. Investigar é ir além da transferência de conhecimentos. É um leque de possibilidades para caminhar e descobrir novos mundos possíveis, onde o ensinar nesta perspectiva pode ser objeto de superação. Para Freire (2008) é preciso que o ato de educar seja baseado nas experiências de vida dos estudantes, e da realidade da comunidade, onde a leitura da palavra se transforme em leitura de mundo, de forma crítica.

O professor 2 ao ser questionado sobre o processo de construção de uma investigação revela que utilizou vários recursos didáticos para facilitar a provocação e instigação dos alunos:

\section{Quadro 2: Resposta de um dos coordenadores sobre a construção da investigação Fonte:} Dados da Pesquisa.

Professor 2: "vai desde o livro didático, sites na internet, conversas nas mídias sociais (WhatsApp e Facebook), roteiros do Mão na Massa e do Toys Fom Trash, que é uma proposta de um indiano disponivel na internet, onde propõe 1 milhão de experimentos para 1 bilhão de pessoas. As propostas do site estão sendo adaptadas, associadas às perguntas e problemas científicos, conectados ao dia a dia do MCRF."

Aqui cabe discutir que os problemas científicos foram contextualizados com os problemas da realidade da comunidade. A metodologia da Pedagogia da Pergunta para problematizar a realidade revelou que aprender é algo permanente e se faz através da 
busca, da curiosidade e da indagação, "em torno de si e de si no e com o mundo e com os outros, preocupando sempre com o amanhã" (FREIRE, 1985, p. 02).

As fotos abaixo registram e ilustram o cotidiano do MCRF: sala de reuniões, alguns experimentos construídos e itinerância.

Fotografia 1: Sala do MCRF Fonte: Fotos tiradas pelos autores.

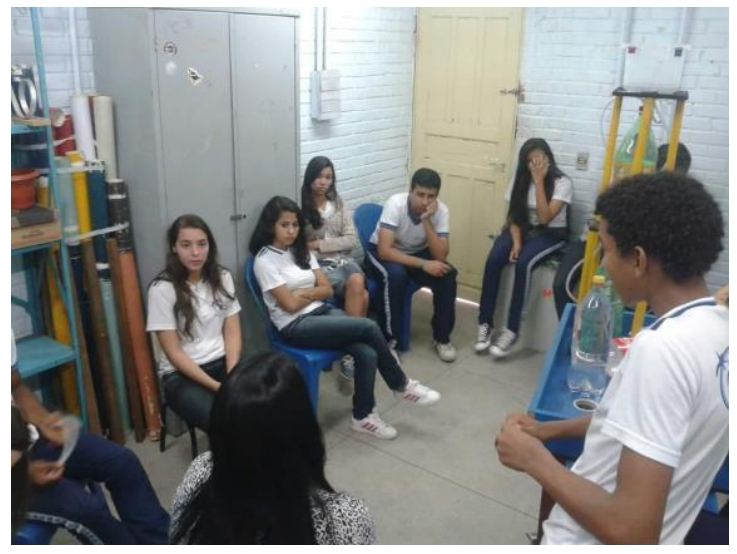

Fotografia 2: Experimentos em exibição no Circo da Ciência - SBPC 2017 Fonte: Acervo dos autores.

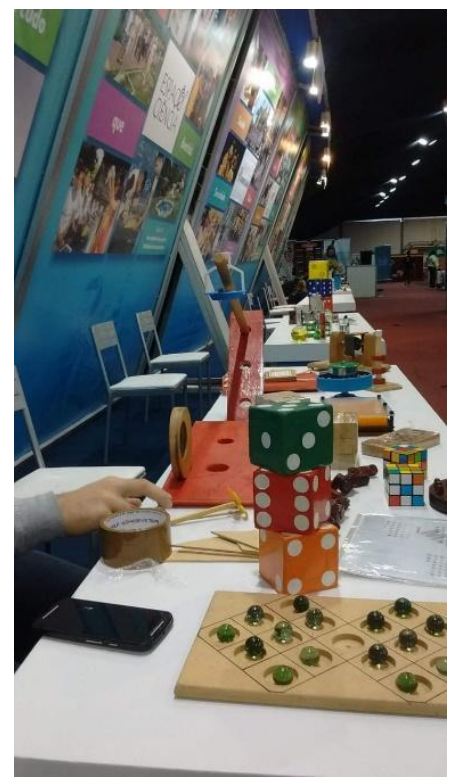

Fotografia 3: Apresentação no Ciência Jovem/PE Fonte: Acervo dos autores. 


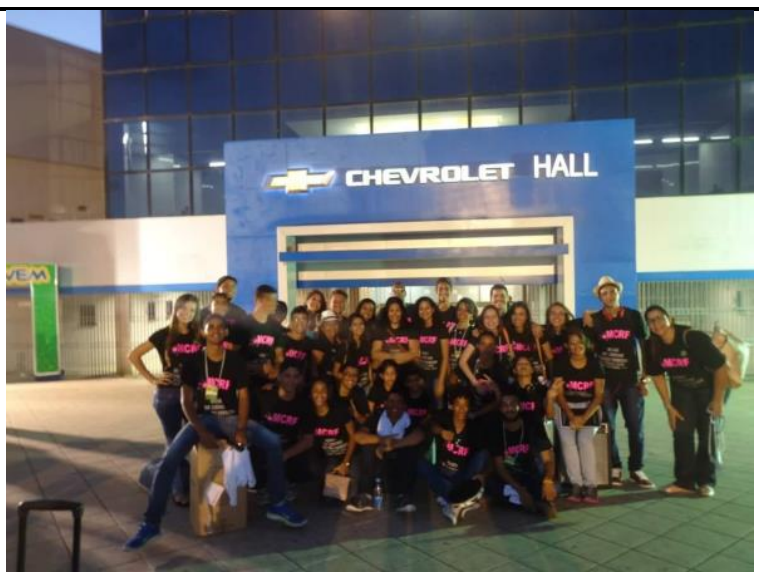

Um dos desafios está em problematizar questões que possam ser experimentais, associadas às questões sociais com a contextualização regional, ou seja, popularizar a ciência numa linguagem do território. Será que pode ser utilizado o contexto? A pesquisa revelou que a história, a cultura, o social são premissas para a construção do conhecimento científico. Neste contexto freireano, a realidade, a história e a valorização dos conhecimentos prévios são pré-condições para a apropriação dos conhecimentos científicos. A condição da prática social, onde toda pessoa sabe alguma coisa, assim como ninguém domina todo o saber. Estes conhecimentos são chamados de senso comum, que devem ser considerados no processo de construção da consciência nas relações com o outro, em forma de diálogo. Só existe saber na invenção, na reinvenção, na busca inquieta, impaciente e permanente que os homens fazem no mundo, com o mundo e com os outros (FREIRE, 2009).

Sobre esta forma de desenvolver o trabalho em sala de aula e no museu o professor 1 relata que:

Quadro 3: Resposta de um dos coordenadores sobre educação contextualizada no MCRF. Fonte: Dados da Pesquisa.

Professor 1: "No MCRF os desafios científicos da química, história, física, biologia e matemática são experimentados e associados ao cotidiano dos jovens. Ainda não sei se é um espaço não formal ou um laboratório didático de ciências nossas ações vão além destas características. Podemos afirmar que o MCRF é uma ideia que se metamorfoseia em um movimento que faz parte da rotina dos estudantes e também do currículo e Projeto Político Pedagógico da escola. $O$ que foge do modelo tradicional de "Clube de Ciências." 
A institucionalização não foi um processo fácil, os próprios professores da escola no início da construção do MCRF, criaram obstáculos. Mas com o passar do tempo, foi reconhecido como um espaço legítimo dos alunos e dos professores. Assim, incluído no Projeto Político Pedagógico - PPP da escola bem como, aceito como membro e da Associação Brasileira de Centros e Museus de Ciência - ABCMC, constando no guia de instituições, em conjunto com 268 espaços do País. O MCRF fez parte da diretoria da gestão da ABCMC (2015 - 2019).

Antes das questões mais atuais do MCRF, os professores da escola sempre participaram ativamente de formação continuada, como centro de referência, que foi implementado pelo Espaço Ciência/PE, nos anos 90 e também das provocações do ABC na Educação Científica: Mão na Massa. A escola, com a institucionalização do MCRF, intensificou a participação e realização de mostras e feiras de ciências, teatro científico, exposições e oficinas. Mas será que o MCRF é um recurso didático?

\section{Quadro 4: Resposta de um dos coordenadores sobre o MCRF enquanto recurso didático e institucionalização. Fonte: Dados da Pesquisa.}

Professor 2: "[...] a intenção era montar um grande espaço na cidade de Petrolina, mas por questões políticas o sonho é concretizado de forma pragmática no MCRF, que é hoje legitimado e reconhecido na SBPC. A intenção era popularizar a ciência num diálogo direto com o povo. Os participantes desde o início determinaram que a educação contextualizada com o semiárido seria um apoio para as ações. Neste sentido, o MCRF é um recurso didático, mas vai além."

A construção, exibição e exploração dos experimentos possibilitaram o conhecer, apresentar e mostrar para as pessoas o que foi pesquisado e investigado. Tais pesquisas, resultado de um trabalho coletivo, são resultantes da união entre as ciências humanas e naturais, sem perder o contexto da realidade dos próprios alunos e da comunidade onde o museu está inserido.

A formação de alunos autônomos possibilita não só uma reflexão da realidade, mas o ir além, que Freire chamou de "ser mais". Só é possível "ser mais" numa busca 
humana, através da curiosidade e da busca do conhecimento de si mesmo, do outro e do mundo. Na Pedagogia do Oprimido, Freire concebe "ser mais" como desafio a libertação dos oprimidos como busca de humanização. A partir do diálogo crítico e problematizador (STRECK, 2019, p. 426)."

Ao ser questionado sobre a influência do MCRF sua vida estudantil, o Estudante A respondeu que:

Quadro 5: Resposta do Aluno A sobre a influência do MCRF na vida. Fonte: Dados da Pesquisa.

Estudante A: "[...] considero o museu como a maior influência na vida pois, foi onde consegui a "desconstrução" do conhecimento onde o pensamento moldado desde início da vida letiva, onde decoro algumas páginas do livro para uma avaliação para em seguida decorar o sucessivo assunto para uma outra forma que se dá apenas a temática, formular a resposta e se corre atrás das respostas e sempre que se chega com uma resposta se formula outra pergunta e assim por diante. O que contribuiu para abrir a minha mente e ver que o conhecimento dito pelo professor do método "tradicional" que se era passado não se compara o que se pode aprender e que a busca pelo conhecimento não pode acabar."

No questionário foram feitas perguntas sobre o cientista Ricardo Ferreira, com a ideia de analisar se os alunos conhecem e se interessam por cientistas brasileiros. Qual a importância do cientista Ricardo Ferreira para a ciência brasileira?

Quadro 6: Resposta do Estudante B sobre a importância do Professor Ricardo Ferreira. Fonte: Dados da Pesquisa.

Estudante B: "O saudoso Professor Ricardo de Carvalho Ferreira, foi um dos físico-químicos brasileiros mais importantes de sua geração, tendo publicado o primeiro trabalho de química teórica inteiramente concebido e desenvolvido na América Latina. Em vida fez numerosas contribuições em diversas áreas da química, física, biologia molecular, história e filosofia da ciência. Foi um dos fundadores da Sociedade Brasileira de Química e da Sociedade Brasileira de História da Ciência, e membro da Academia Brasileira de Ciências, depois de sua partida continua incentivando a divulgação científica pelo sertão Pernambuco, através do Museu de Ciências que leva seu nome."

Dados da pesquisa sobre Percepção Pública da Ciência, em 2010, revelam que “71\% dos muito interessados em ciência e tecnologia, não souberam informar o nome 
de nenhuma instituição científica do Brasil e $82 \%$ não conheciam o nome de nenhum cientista brasileiro" (MORAES et al., 2017).

Neste sentido, incentivar os alunos a conhecerem cientistas brasileiros vem sendo provocado no MCRF. A perspectiva de valorizar e reconhecer a carreira de cientista vem sendo uma discussão permanente entre os integrantes do projeto.

Também foi questionado aos estudantes qual era a missão do MCRF, ao que responderam:

Quadro 7: Resposta dos Estudantes C e D sobre a missão do MCRF. Fonte: Dados da Pesquisa.

Estudante C: "Melhorar na educação, incentivar o aluno a pesquisar, elaborar projetos com questões sociais e interagir na sociedade".

Estudante D: "Mudar o curso da vida dos alunos participantes, instigando o questionamento e colocar os alunos para pôr a mão na massa e tentando assim mudar sua perspectiva de vida."

Educar com o espírito da investigação ainda é um desafio contemporâneo em nossas escolas, pois a Educação Científica precisa estar alinhada com a ação de vários outros setores. Nesse sentido, a criação de um espaço não formal, (museu de ciência) dentro de um ambiente formal (escola), pode ser uma possibilidade para provocar os modelos de laboratórios de ciências existentes nas instituições de educação básica, extrapolando os limites estabelecidos pelas paredes da escola e expandindo os horizontes de alunos, professores e comunidade. As respostas dos Estudantes B e C à pergunta "Como o MCRF influencia sua vida estudantil?" trazem referências a esta expansão:

Quadro 8: Resposta dos Estudantes B e C sobre a influência do MCRF. Fonte: Dados da Pesquisa.

Estudante B: "O MCRF tornou-se um projeto de vida, antes de viver o Museu, eu não tinha noção do tamanho do mundo, nem da minha capacidade pessoal. Através do MCRF pude perceber o quão importante é a divulgação científica. Além de me dedicar enquanto estudante do Ensino Médio em atividades além quadro negro, paredes e carteiras, pois o Museu revela o mundo existente além paredes da sala de aula clássica."

Estudante C: "No início o Museu para mim antes era só uma diversão, um meio de distração, porém percebi que hoje é muito mais do que isso, é meu refúgio, geralmente quando estou triste 
ou estressado, a partir do momento que começo a fazer algo do Museu é como se eu esquecesse tudo, ele também é uma das minhas fontes de aprendizagens, aprendo muito com os experimentos, principalmente porque pegamos o que sabemos da teoria e jogamos na prática. Antes eu odiava Química e Física, biologia nem tanto, mas hoje pude ver que essas matérias estão presentes a todo momento na nossa vida, nós que às vezes não prestamos atenção ou não sabemos. Estou muito feliz de estar participando de um Projeto como o Museu, sei que futuramente isso vai me servir muito. E todo aprendizado que estou adquirindo hoje não é em vão."

Os depoimentos dos alunos também revelaram a importância desse processo de interação direta com o mundo e com os objetos, tanto física (hands on) e emocional (hearts on), quanto intelectual (minds on) e também o contexto cultural na abordagem e diálogos estabelecidos por estes nas apresentações realizadas em eventos em diversas partes do país, além de eventos internacionais (BASSOLI, 2014).

Para finalizar, as ações do MCRF foram divulgadas nos seguintes eventos: Circo da Ciência da $A B C M C$, nas reuniões anuais da Sociedade Brasileira para o Progresso da Ciência - SBPC ocorridas no Rio Branco/AC, São Carlos/SP, Porto Seguro/BA, Belo Horizonte/MG e Maceió/AL, além de feiras de ciências, mostras científicas, palestras e oficinas, sendo essas embasadas em elucidações sobre a aplicação do referido método. Os resultados obtidos foram evidenciados pelo número de participantes (alunos da escola e integrantes do MCRF), que nesse período já ultrapassou o número de 300 estudantes. Ainda as atividades, em 2016, foram apresentadas palestras nos Encontros de Física do Instituto Federal de Educação do Sertão Pernambucano-IF Sertão, apresentação de trabalhos no Ciência Jovem dos anos 2012 a 2017, Seminário na Universidade Federal do Vale do São Francisco - UNIVASF/Campus Senhor do Bonfim/BA, 2014, I Encontro do ABC na Educação Científica: Mão na Massa na UESC em Ilhéus/BA, 2014. Em 2017, ganhou o prêmio "Qualidade do Ensino e Gestão da Sala de Aula", do estado de Pernambuco. Representou o Brasil 7th Latinamerican ExpoSciences ESI-AMLAT 2014, Medellin, Colômbia. Parceria com SESC/Petrolina para a SNCT, 2015 a 2017. 
O MCRF traz como destaque em suas ações (Tabela 1), os projetos desenvolvidos e apresentados, entre os anos de 2012 e 2017, na Ciência Jovem do Espaço CiênciaPE, que é a maior feira da região Nordeste, uma das mais importantes do Brasil. Os projetos desenvolvidos foram nas áreas de Meio Ambiente, Energia, Vida e Saúde, CTSA e Cultura e Arte, assim como a utilização de materiais de baixo custo ou recicláveis como garrafa PET, tecido, papelão e cola.

Tabela 1: Projetos de pesquisas desenvolvidos e apresentados durante o Ciência Jovem/PE (2012 a 2017).

\begin{tabular}{|c|c|c|}
\hline Ano & $\begin{array}{c}\text { Projetos Apresentados no } \\
\text { Ciência Jovem - Espaço Ciência - } \\
\text { PE }\end{array}$ & Perguntas/Temas Geradores \\
\hline \multirow{3}{*}{2012} & $\begin{array}{l}\text { Resíduos Sólidos: Desperdício de } \\
\text { Alimentos }\end{array}$ & $\begin{array}{l}\text { Como reaproveitar a merenda escolar que sobra do } \\
\text { almoço? }\end{array}$ \\
\hline & $\begin{array}{l}\text { Fogão Solar: Desbravando o } \\
\text { Sertão Pernambucano }\end{array}$ & $\begin{array}{l}\text { Como utilizar a energia solar para cozinhar alimentos } \\
\text { no Semiárido? }\end{array}$ \\
\hline & $\begin{array}{l}\text { Atividades Lúdicas com } \\
\text { Materiais de Baixo Custo }\end{array}$ & Como reaproveitar material de baixo custo? \\
\hline \multirow{3}{*}{2013} & Ar Que Respiramos & $\begin{array}{l}\text { Será que os locais utilizados para atividade física, ao ar } \\
\text { livre, em Petrolina/PE, são adequados? }\end{array}$ \\
\hline & $\begin{array}{l}\text { Museu de Ciências Ricardo } \\
\text { Ferreira - MCRF }\end{array}$ & $\begin{array}{l}\text { Será que é possível integrar Ciência, Tecnologia, } \\
\text { Sociedade e Ambiente (CTSA)? }\end{array}$ \\
\hline & Grêmio Art-Científico & $\begin{array}{l}\text { Como integrar a diversidade científica, artística e } \\
\text { cultural da escola? }\end{array}$ \\
\hline \multirow{3}{*}{2014} & Escutando a Luz & $\begin{array}{l}\text { Como incluir e integrar a pessoa com deficiência } \\
\text { auditiva? }\end{array}$ \\
\hline & Rádio ComCiência do Sertão & $\begin{array}{l}\text { Como montar uma rádio escola? De que maneira } \\
\text { gerenciar uma rádio escola? }\end{array}$ \\
\hline & Águas do Velho Chico & $\begin{array}{l}\text { Será que os esgotos despejados sem tratamento no } \\
\text { rio, não prejudicam sua manutenção? }\end{array}$ \\
\hline
\end{tabular}




\begin{tabular}{|c|c|c|}
\hline \multicolumn{3}{|c|}{ 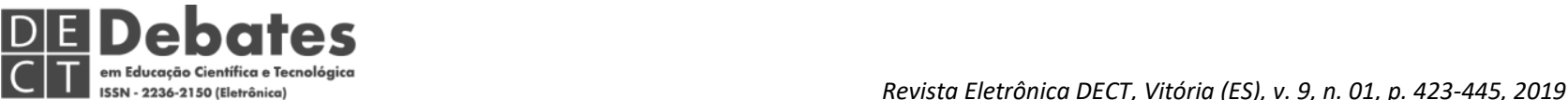 } \\
\hline \multirow[b]{2}{*}{2016} & Agrotóxico: O Mal Invisível & $\begin{array}{l}\text { De que maneira são usados e descartados os } \\
\text { agrotóxicos e quais seus impactos na saúde humana? }\end{array}$ \\
\hline & $\begin{array}{l}\text { Protótipo Biomecânico de Baixo } \\
\text { custo para a Recuperação de } \\
\text { Membros Inferiores }\end{array}$ & Como baratear aparelho de fisioterapia? \\
\hline \multirow{3}{*}{2017} & Jogos de Química & $\begin{array}{l}\text { Como fazer atividades lúdicas em química através do } \\
\text { baralho? }\end{array}$ \\
\hline & Lixeira Inteligente & $\begin{array}{l}\text { Qual o destino do seu lixo? e quais seus impactos na } \\
\text { saúde humana? }\end{array}$ \\
\hline & Smartscópio & $\begin{array}{l}\text { Como utilizar o celular como ferramenta didática de } \\
\text { microbiologia? }\end{array}$ \\
\hline
\end{tabular}

\section{CONSIDERAÇÕES FINAIS}

Os resultados revelaram que as experiências de um Museu de Ciência dentro de uma escola podem contribuir para a superação de problemas recorrentes como evasão, reprovação e desestímulo. Abrindo e ampliando novas possibilidades educacionais com o desenvolvimento da habilidade dos estudantes na criação de critérios para compreensão de objetos, fenômenos ou fatos do cotidiano, empíricos ou científicos.

A partir da análise das falas dos alunos e dos professores, pode-se perceber que estes atores estão abertos a realizarem atividades com preceitos freireano, utilizando a investigação e a Pedagogia da Pergunta, Temas Geradores, Rodas de Conversas e a Dialogicidade, para promover uma leitura e entendimento e si, do outro e do mundo. Mas é preciso a intencionalidade do professor para não fazer qualquer pergunta descontextualizada. É importante o acompanhamento permanente do MCRF enquanto experiência educativa.

As exibições, itinerâncias, seminários e mostras dos experimentos do MCRF possibilitaram aos alunos uma aproximação com a ciência e uma formação humana 
integral. A proposta investigativa para construir experimentos proporcionou uma ação transformadora e reflexão sobre a realidade, ou seja, pensar, elaborar hipóteses e pensamento crítico já estão na rotina dos participantes do MCRF. Para freire, as palavras geradoras fundam num universo que converge em Temas Geradores. As palavras são colhidas em diálogos formais e informais, onde o educador ouve, pergunta e problematiza e instiga a curiosidade sobre um contexto ou objeto.

A construção de um espaço não formal com a metodologia investigativa, pode proporcionar à comunidade escolar, refletir sobre um fazer educacional diferente do tradicional. Percebeu-se que o envolvimento dos alunos em participar do Museu de Ciência foi importante para a formação da vida social e científica. As exibições, itinerâncias, seminários e mostras dos experimentos do MCRF possibilitaram contatos com a popularização da ciência, além de mergulhar no mundo do conhecimento científico sem perder o interesse e a curiosidade. A proposta investigativa para construir experimentos vem proporcionando uma reflexão da ação dos alunos, ou seja, pensar e elaborar hipóteses e pensamento crítico já estão na rotina dos participantes. A popularização da ciência incita o observador acomodado com tudo que a ele é imposto a sair da inércia, isto é, os centros e museus de ciências são locais onde se predomina a ação interativa. A experiência do MCRF pode ser uma possibilidade para outras escolas públicas, para provocar os professores e estudantes do ensino básico. O espaço não-formal dentro do formal (escola) colabora para provocar um universo de situações e pesquisas possíveis, bem como trocas de experiências entre os participantes, importantes para o entendimento de como funciona a ciência, e que podem facilitar a aprendizagem.

\section{Agradecimento e Apolo}


Conselho Nacional de Desenvolvimento Científico e Tecnológico - CNPq Coordenação de Aperfeiçoamento de Pessoal de Nível Superior (CAPES) CAPES - Programa Novos Talentos.

Associação Brasileira de Centros e Museus de Ciência - ABCMC. 


\section{REFERÊNCIAS}

ANDRÉ, Marli Eliza Dalmazo Afonso de. Texto, contexto e significado: algumas questões na análise de dados qualitativos. Cadernos de Pesquisa, (45): 66-71.

BARROS, Manoel de. Livro sobre nada. 3. ed. Rio de Janeiro. Record, 1998.

BASSOLI, Fernanda. Atividades práticas e o ensino-aprendizagem de ciência(s): mitos, tendências e distorções. Revista Ciênc. educ. (Bauru) vol.20 no.3 Bauru July/Sept. 2014. Disponível em: http://www.scielo.br/scielo.php?script=sci_arttext\&pid=S151673132014000300579. Acesso em 01 jun. 2018.

BORGES, Rita de Cássia Pereira. Formação de formadores para o ensino de ciências baseado em investigação. 2010. 257 p. Tese (Doutorado - Programa de Pós-Graduação em Educação) - Universidade de São Paulo. São Paulo. 2010.

CARVALHO, Ana Maria Pessoa et al. Ciências no ensino fundamental: o conhecimento físico. São Paulo: Scipione, 1998.

CHARPAK, Georges; LÉNA, Pierre.; QUÉRÉ, Yves. Los niños y la ciencia: la aventura de la mano en la masa. Buenos Aires: Siglo XXI Editores, 2006.

FERREIRA, José Ribamar. Popularização da Ciência e as Políticas Públicas no Brasil (2003-2012). 2014. 185 f. Tese (Doutorado em Ciências Biológicas - Biofísica). Universidade Federal do Rio de Janeiro. Rio de Janeiro, 2014.

FREIRE, Paulo. Pedagogia do oprimido. São Paulo: Paz e Terra, 1974

FREIRE, Paulo. Por uma pedagogia da pergunta. 3 ed. Rio de Janeiro: Paz e Terra. Rio de Janeiro, 1985.

FREIRE, Paulo. Pedagogia da autonomia: saberes necessários à prática pedagógica, Editora Paz e Terra, 37 ed., 2008. (Coleção Leitura), 2008.

FREIRE, Paulo. Educação como prática da liberdade. 3 ed Rio de Janeiro: Paz e Terra. 2009.

FURTADO, Carolina. BAZIN, Maurice: Fundador do centro interativo pioneiro de ciência do Brasil, o Espaço Ciência Viva, Maurice Bazin foi defensor árduo da popularização da ciência e democratização do acesso ao conhecimento. Rio de Janeiro,2013. Anais do II EIDC.

http://www.cienciaviva.org.br/sites/default/files/II_EIDC_Anais.pdf. Acesso em 02 jun. 2018.

GASPAR, Alberto. $O$ " $R$ " de retilíneo. Caderno Brasileiro de Ensino de Física, Florianópolis, v. 11, n. 1, p. 7-10, jan. 1994. ISSN 2175-7941. Disponível em: <https://periodicos.ufsc.br/index.php/fisica/article/view/7260>. Acesso em: 05 jun. 2018. 
GASPAR, Alberto. A educação formal e a educação informal em ciências. 2002. Disponível

em:

http://www.museudavida.fiocruz.br/images/Publicacoes_Educacao/PDFs/cienciaepu blico.pdf . Acesso em 10 mai. 2018.

HAMBURGER, Ernest Wolfgang. Apontamentos sobre o ensino de Ciências nas séries escolares iniciais, Revista de Estudos Avançados, vol.21 N.60. São Paulo, 2007

JACOBUCCI, Daniela Franco Carvalho. A Formação Continuada de Professores em Centros e Museus de Ciências no Brasil. 2006. 317 p. Tese (Doutorado em Educação Universidade Estadual de Campinas). Campinas. SP. 2006.

LIBÓRIO, Victória. Museu de Ciência e Tecnologia da Bahia tem Futuro Incerto. Disponível

em:

(http://www.cienciaecultura.ufba.br/agenciadenoticias/noticias/museu-de-ciencia-etecnologia-da-bahia-tem-futuro-incerto/). Acesso em 10 de maio de 2018.

MARCONI, Marina de Andrade; LAKATOS, Eva Maria. Técnicas de pesquisa: planejamento e execução de pesquisas, amostragens e técnicas de pesquisa, elaboração, análise e interpretação de dados. 7. ed. 7. reimpr. São Paulo: Atlas, 2013. MASSARANI, Luísa. Guia de Centros e Museus de Ciência do Brasil 2015. Rio de Janeiro. 2015.

http://www.abcmc.org.br/publique1/cgi/cgilua.exe/sys/start.htm?sid=26. Acesso em 13 de mai de 2018

MORAES, Bruno et. Al, 2017. Pesquisa revela que brasileiro gosta de ciência, mas sabe pouco sobre ela. Campinas. Disponivel em: https://www.unicamp.br/unicamp/ju/noticias/2017/09/25/pesquisa-revela-quebrasileiro-gosta-de-ciencia-mas-sabe-pouco-sobre-ela. Acesso em 01 de maio de 2018.

MORAES, Roque; LIMA, Valderez M. do R. (org). Pesquisa em sala de aula: tendências para a educação em novos tempos. 2.ed. Porto Alegre: EdiPUCRS, 2004.

MOREIRA, Herivelto; CALEFFE, Luiz Gonzaga. Metodologia da pesquisa para o professor pesquisador. Rio de Janeiro: DP\&A, 2006.

PAVÃO, Antônio Carlos. Ensinar ciências fazendo ciência com professores e alunos da educação básica. 2008. Disponível em http://hpc.ct.utfpr.edu.br/ charlie/docs/PPGFCET/4_TEXTO_01_ENSINAR\%20CI\%C3 \%8ANCIAS\%20FAZENDO\%20CI\%C3\%8ANCIA.pdf. Acesso em 15 de abr. de 2018.

SANPIERI, Roberto Hernandez.; COLLADO, Carlos Fernández,; LUCIO, Maria del Pliar Baptista. Metodologia de Pesquisa. São Paulo: McGrawHill. 2006. 
STRECK, Danilo. R.; REDIN, Euclides.; ZITKOSKI, Jaime José (Orgs.). Dicionário Paulo Freire. 3. ed. rev. e ampl. Belo Horizonte: Autêntica Editora, 2019.

TRIVIÑOS, Augusto N. S. Introdução à pesquisa em ciências sociais: a pesquisa qualitativa em educação. São Paulo: Atlas, 1987.

UNESCO. Science for the twenty-first century. Paris, 2000. Disponível em: http://unesdoc.unesco.org/images/0012/001229/122938eo.pdf. Acesso em 15 mai. de 2018

VALENTE, Maria Ester.; CAZELLI, Sibelle.; ALVES, Fátima. Museus, ciência e educação: novos desafios. História, Ciências, Saúde - Manguinhos, v. 12, n. suplemento, p. 183203, Rio de Janeiro. 2005. Disponível em: http://www.scielo.br/pdf/hcsm/v12s0/09. Acesso em 25 mai de 2018. 